\title{
PHASE CHANGE IN ADSORBED HELIUM AT LOW TEMPERATURE*
}

\author{
D. L. Goodstein, $†$ J. G. Dash, and W. D. McCormick \\ University of Washington, Seattle, Washington \\ (Received 20 July 1965)
}

Several recent reports indicate a growing interest in the properties of adsorbed helium at low temperatures. This interest is based on the expected influence of restrictions of mobility and dimensions on thermodynamic properties such as heat capacity, ${ }^{1,2}$ adsorption isotherms ${ }^{3}$ magnetic susceptibility, ${ }^{4-6}$ and nuclear polarization. ${ }^{7}$ This Letter presents specificheat data for adsorbed helium in the temperature range from 0.25 to $4^{\circ} \mathrm{K}$, at several partial monolayer coverages. We interpret the results as indicating the existence of two surface phases.

Our calorimeter consists of a copper sponge prepared by sintering $3 \mu$ copper powder into a vacuum-tight copper container. ${ }^{8}$ Monolayer capacities for nitrogen and argon were measured by gas adsorption at $77^{\circ} \mathrm{K}$ and analyzed by the method of Brunauer, Emmett, and Teller. ${ }^{9}$ The $\mathrm{N}_{2}$ and Ar monolayer capacities, amounting to approximately $12 \mathrm{~cm}^{3}$ at standard temperature and pressure (STP), indicate a calorimeter surface area of about $50 \mathrm{~m}^{2}$. A quantity of Ar equivalent to one monolayer was mixed with each charge of helium sealed into the calorimeter. The Ar was added in order to provide a more uniform substrate for the adsorbed helium, and it was hoped that the weaker argonhelium interaction would make the helium more mobile on this surface than on bare copper. The Ar monolayer was formed before each experiment by cooling the apparatus slowly through the temperature range in which the Ar was adsorbed. At these temperatures practically none of the He was adsorbed on the copper; but the adsorption of the He on the Ar surface was essentially complete at liquid-helium temperatures. The vapor pressure of a monolayer of He on preadsorbed $\mathrm{Ar}$ at $4.2^{\circ} \mathrm{K}$ was measured to be less than $10^{-3}$ Torr, so that no vaporization correction to the heat capacities had to be made. At $4.2^{\circ} \mathrm{K}$ the monolayer capacities of $\mathrm{He}$ on preadsorbed $\mathrm{Ar}$ were 1.32 atoms $\mathrm{He}^{4}$ and 1.18 atoms $\mathrm{He}^{3}$ per atom of adsorbed $\mathrm{Ar}$. We ascribe the difference to zero-point energy: A similar effect appears to have been observed for adsorption on activated charcoal. ${ }^{10}$

The sealed calorimeter was connected to a potassium-chrome-alum-salt capsule via a
$\mathrm{Pb}$ superconducting heat switch. The thermometer was a $100-\Omega, \frac{1}{2}-\mathrm{W}$ Speer resistor calibrated against the $\mathrm{He}^{4}$ bath vapor pressure and the magnetic susceptibility of the $\mathrm{KCr}$ alum salt. The heat capacity of the adsorbed helium, which amounted to 10 to $30 \%$ of the total, was obtained by subtracting the heat capacity of the empty calorimeter. Independent runs of the empty calorimeter with and without Ar disclosed no difference.

The specific-heat results are presented in Fig. 1. Curves I and II for $\mathrm{He}^{3}$ and $\mathrm{He}^{4}$ at essentially the same density are fitted by

$$
\begin{aligned}
& C / R\left(\text { curve } \mathrm{I}, \mathrm{He}^{3}\right)=(0.030 \pm 0.003) T^{2}, \\
& C / R\left(\text { curve II, } \mathrm{He}^{4}\right)=(0.038 \pm 0.003) T^{2}, \\
& 0.25^{\circ}<T<3^{\circ} \mathrm{K} .
\end{aligned}
$$

These results may be interpreted in terms of a two-dimensional Debye model, obeying the theoretical expression for $T \ll \theta$,

$$
C=28.8 R(T / \theta)^{2} \text {. }
$$

The experimental values for $\theta$ are $31 \pm 1^{\circ}$ for $\mathrm{He}^{3}$ and $28 \pm 1^{\circ}$ for $\mathrm{He}^{4}$. The ratio of coefficients of $T^{2}$ for the two isotopes should be the same as the ratio of their masses, 0.75. The measured value is 0.79 .

A $T^{2}$ dependence with a Debye temperature of $28^{\circ}$ has been found for a monolayer of $\mathrm{He}^{4}$ on Vycor glass for $T$ between 0.5 and $2.5^{\circ} \mathrm{K}$ in a recent study by Brewer, Symonds, and Thomson. ${ }^{11}$ Steele and Ross ${ }^{12}$ found a molar heat capacity of $2 R \pm 25 \%$ for $\mathrm{He}^{4}$ at monolayer coverage on $\mathrm{TiO}_{2}$ at $10^{\circ} \mathrm{K}$. If $\theta \approx 20^{\circ}$, one would expect $C \approx 1.7 R$ at this temperature. Band ${ }^{13}$ has pointed out that the lowest coverage results in Frederikse's early measurements ${ }^{14}$ in a narrow temperature range near $2^{\circ} \mathrm{K}$ were consistent with a $T^{2}$ dependence and a Debye $\theta \approx 18^{\circ}$.

We find that a relatively small change in surface density of $\mathrm{He}^{4}$ produces a qualitative change in the heat capacity. A decrease in coverage from 0.53 to 0.41 layer causes an increase of more than a factor of two in the heat capacity per atom at all temperatures. At this coverage the temperature dependence is no longer as $T^{2}$, but is more closely described by a term 


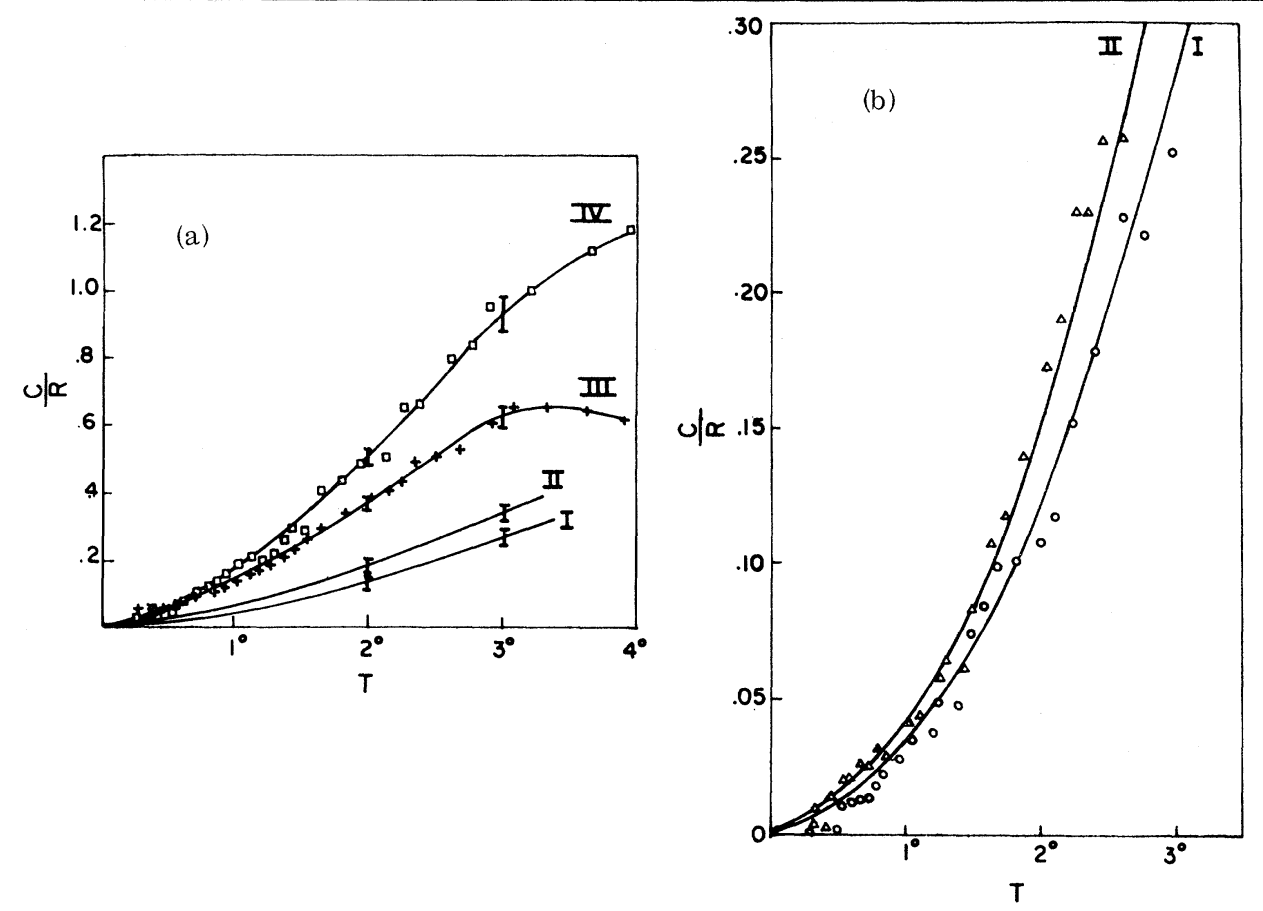

FIG. 1. Heat capacity of adsorbed helium. $\bigcirc$, curve I, $8.09 \mathrm{~cm}^{3} \mathrm{STP} \mathrm{He}^{3}, 0.57$ layer. $\triangle$, curve $I$, $8.29 \mathrm{~cm}^{3}$ STP $\mathrm{He}^{4}, 0.53$ layer. +, curve III, $6.54 \mathrm{~cm}^{3} \mathrm{STP} \mathrm{He} \mathrm{He}^{4}, 0.41$ layer. $\square$, curve IV, $3.23 \mathrm{~cm}^{3} \mathrm{STP} \mathrm{He}^{4}, 0.20$ layer. Estimated maximum uncertainties are shown by error bars at 2 and $3^{\circ}$. (b) has a more suitable scale for showing curves I and II.

linear in $T$ over the range 0.3 to $1.4^{\circ} \mathrm{K}$. Above $1.4^{\circ} \mathrm{K}$, the heat capacity goes through a broad maximum; these features can be seen in curve III of Fig. 1. A further decrease in density, to 0.20 layer, increases the heat capacity further, but the maximum is lost: The data are shown on curve IV. We believe that the differences between curves I-II and III-IV imply that a firstorder phase change is taking place on the surface. If curves III and IV represent equilibrium between two coexisting phases, the heat capacity would be composed of three primary terms, one for each phase and one for the heat of transformation from one phase to the other. The maximum of curve III could arise from a competition among these three terms. In Fig. 2 we present a hypothetical phase diagram for such a situation, indicating the possible paths for curves I and III. Crossing of the boundary from a two-phase into a single-phase region would be marked by a discontinuity in the heat capacity, but no discontinuity has been seen, perhaps because the experimental range did not extend to high enough temperatures. It is hoped that further experimental study will allow us to trace out a phase diagram.

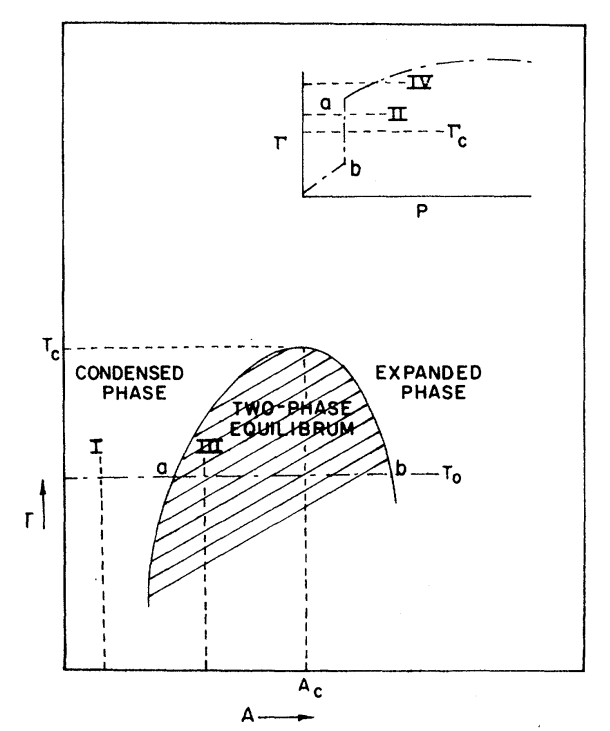

FIG. 2. Examples of a possible two-dimensional phase diagram; molar area, $A$, versus temperature, $T$. Inset is an adsorption insotherm at temperature $T_{0}$ (pressure versus coverage $\Gamma=1 / A$ ) corresponding to the labeled isotherm at $T_{0}$ on the larger figure; the vertical rise spans the two-phase region from point $a$ to point $b$. 
In films of monolayer coverage or less, twodimensional first-order phase changes are expected. Vertical rises have been observed in adsorption isotherms ${ }^{15}$ (see isotherm in Fig. 2); they are cited as evidence of phase transitions, but no indication of such transitions has previously been found in heat-capacity measurements. ${ }^{16-20}$

\footnotetext{
*Work sponsored by the U. S. Air Force Office of Scientific Research, Grants No. AF-AFOSR62298 and No. AF-AFOSR92365.

$\dagger$ National Aeronautics and Space Administration Predoctoral Trainee.

${ }^{1}$ M. H. Lambert, Phys. Rev. Letters 12, 67 (1964); 13, 266E (1964).

${ }^{2}$ D. L. Goodstein, W. D. McCormick, and J. G. Dash, Proceedings of the Ninth International Conference on Low Temperature Physics, Columbus, Ohio, 1964 (to be published).

${ }^{3}$ D. F. Brewer, A. J. Symonds, and A. L. Thomson, Proceedings of the Ninth International Conference on Low Temperature Physics, Columbus, Ohio, 1964 (to be published).

${ }^{4}$ G. Careri, M. Santini, and G. Signorelli, Proceedings of the Ninth International Conference on Low Temperature Physics, Columbus, Ohio, 1964 (to be published).
}

${ }^{5}$ G. Careri, M. Santini, and G. Signorelli, Phys. Letters $\underline{4}, 61$ (1963); $\underline{5}, 102$ (1963).

${ }^{6} \mathrm{H}$. Weinstock and C. E. Long, Proceedings of the Ninth International Conference on Low Temperature Physics, Columbus, Ohio, 1964 (to be published).

${ }^{7}$ L. Passell and R. I. Schermer, Bull. Am. Phys. Soc. 10, 30 (1965).

${ }^{8}$ Suggested by D. O. Edwards, private communication. ${ }^{9}$ See, for example, D. M. Young and A. D. Crowell, Physical Adsorption of Gases (Butterworths Scientific Publications, Ltd., London, 1962), p. 190.

${ }^{10}$ C. J. Hoffman, F. J. Edeskuty, and E. F. Hammel, J. Chem. Phys. 24, 124 (1956).

${ }^{11}$ D. F. Brewer, A. J. Symonds, and A. L. Thomson, private communication.

${ }^{12}$ W. Steele and M. Ross, J. Chem. Phys. $\underline{35}, 862$

(1962).

${ }^{13}$ W. Band, Phys. Rev. 76, 441 (1949).

${ }^{14}$ H. P. R. Frederickse, Physica 15, 860 (1949).

${ }^{15}$ Young and Crowell, reference $9, \mathrm{p} .120$ and following.

${ }^{16}$ R. J. Bobka, R. E. Dininny, A. R. Siebert, and E. L. Pace, J. Phys. Chem. 61, 1646 (1957).

${ }^{17}$ J. A. Morrison, J. M. Los, and L. E. Drain, Trans. Faraday Soc. 47, 1023 (1951).

${ }^{18}$ L. E. Drain and J. A. Morrison, Trans. Faraday Soc. 49,654 (1953).

${ }^{19}$ E. L. Pace, W. T. Berg, and A. R. Siebert, J. Am. Chem. Soc. 78, 1531 (1956).

${ }^{20}$ E. L. Pace, D. J. Sasmer, and E. L. Heric, J. Am. Chem. Soc. 74, 4473 (1952).

\title{
RELAXATION OF EXCITON STATES IN ALKALI-HALIDE CRYSTALS*
}

\author{
R. F. Wood
}

Solid State Division, Oak Ridge National Laboratory, Oak Ridge, Tennessee (Received 24 May 1965)

Based on experience gained from calculations on the $F$ center, ${ }^{1}$ we recently suggested ${ }^{2}$ that lattice relaxation may play an important role in the interpretation of absorption, emission, and photoconductivity experiments in pure ionic crystals-especially the alkali halides. We report briefly here the results of calculations on exciton states in $\mathrm{NaCl}$ and $\mathrm{KCl}$ which we feel give support to the validity of this suggestion.

The absorption spectra of many alkali-halide crystals exhibit a sharp, intense peak (spinorbit splitting neglected) in the uv, followed successively at higher energies by a step, or shoulder, and a second intense, usually sharp, peak. Since the photocurrent often shows a steep rise in the region of the absorption spectra corresponding roughly to the shoulder, it is usual- ly concluded that the shoulder must represent the onset of band-to-band transitions. In that case, the excited state responsible for the second peak would appear to lie in the conduction band, and there has been considerable speculation as to why the peak is as sharp and intense as it is. We believe that our calculations show that it is possible for photoconductivity to occur without necessarily implying direct transitions to conduction band states. They also indicate that, whereas the energy of the manyelectron excited state responsible for the second absorption peak may lie in the band of energies of the many-electron conduction states (polaron states), the single-particle function describing the electron principally involved in the transition is localized. 